INVESTIGACIONES

de HISTORIA ECONÓMICA

2005, invierno, número 1. Pp. 131 a 161

\title{
Hacia un cártel perfecto. Los acuerdos colusivos en el sector siderúrgico español (1871-1907)
}

\author{
Towards a perfect cartel. Collusion in the Spanish iron and \\ steel industry (1871-1907) \\ MIGUEL ÁNGEL SÁEZ GARCÍA \\ Universidad de Alicante
}

RESUMEN

El objetivo de este trabajo es analizar el proceso de cartelización de la siderurgia moderna española desde los primeros acuerdos de precios en 1871 hasta la creación de la Central Siderúrgica en 1907. A partir de documentación primaria obtenida de archivos de empresas siderúrgicas, el artículo estudia el funcionamiento interno de los carteles y las dificultades a las que se enfrentaban para detectar a los transgresores de los acuerdos y para evitar la competencia de las fábricas libres. Por otra parte, se pretende contribuir al debate sobre la responsabilidad de la oferta en la estructura del mercado siderúrgico español y su influencia en el proceso de industrialización español.

PALABRAS CLAVE: Cárteles, Industrialización, Mercados siderúrgicos, Siderurgia.

Códigos JEL: L41, N63, N84, O14

\section{ABSTRACT}

The aim of this work is to analyse the process of cartelisation in the modern Spanish iron and steel industry from the first pricing agreements in 1871 to the creation of the Central Siderúrgica in 1907. Using documentation from archives of iron and steel companies, the article studies the internal operation of the cartels and the difficulties faced in detecting cheating and in avoiding competition from free riders. The work also aims to contribute to the debate on the responsibility of supply within the structure of the Spanish iron and steel market and its influence on the Spanish industrialization.

KEY WORDS: Cartels, Industrialization, Iron and steel markets, Iron and steel industry.

JEL Codes: L41, N63, N84, O14 
S on muchos los trabajos que han destacado el elevado nivel de cartelización alcanzado por la siderurgia española en las primeras décadas del siglo XX y en particular desde 1907, momento en el que la mayor parte de las empresas se unieron para crear la Central Siderúrgica ${ }^{1}$. Existen numerosas referencias a dicho organismo y a su precedente, el Sindicato Siderúrgico, en las monografías sobre la siderurgia española. Sin embargo, carecemos de trabajos que se hayan centrado en el estudio de los acuerdos colusivos previos a la Central Siderúrgica y que hayan analizado el funcionamiento interno de los mismos, lo que probablemente es debido al escaso interés que ha suscitado el tema de la distribución frente a los aspectos productivos ${ }^{2}$.

El objetivo de este artículo es analizar la cartelización del sector desde los primeros acuerdos de precios en 1871 hasta que se creó la central de ventas en 1907. El trabajo se centrará en los carteles de hierros y aceros comerciales, dejando de lado los relativos al lingote de hierro o el acuerdo alcanzado por Altos Hornos de Bilbao y La Vizcaya para repartirse los mercados de palanquilla, llantón, carriles y viguetas. El motivo por el que no se analizarán estos últimos es que su producción estaba limitada a un número muy reducido de empresas muy concentradas geográficamente (Vizcaya) ${ }^{3}$. Por lo tanto, las circunstancias facilitaban el logro de acuerdos colusivos. Además, el reducido número de miembros hacía que los acuerdos de precios y reparto de mercado gozasen de gran estabilidad. Esto era debido a que, por un lado, detectar a los transgresores era relativamente sencillo y, por otro, los incentivos para incumplir los acuerdos eran reducidos, pues la ruptura del cártel depararía una situación de competencia vía precios que reduciría los beneficios de todos los participantes dada la similitud en los costes de producción y la estrechez del mercado español. En definitiva, la falta de incentivos para transgredir el acuerdo hacía que se

1 Este trabajo se ha beneficiado de la financiación concedida a través del proyecto de investigación 1/UPV/EHU 00012.321-HA-7884/2000 de la Universidad del País Vasco. Quisiera agradecer la ayuda y los comentarios de Pablo Díaz Morlán, Emiliano Fernández de Pinedo, Jesús M. Valdaliso, Carlos Barciela y Francisco Comín, y las sugerencias realizadas por dos evaluadores anónimos, así como las facilidades dadas por el personal del Archivo Histórico del BBVA para la consulta del fondo Bolueta.

2 Sobre la distribución de hierros comerciales a través de la Unión de Almacenistas de Hierros, véase Martínez Ruiz (1998). La cartelización del sector ha sido analizada por Fraile (1991). Referencias más o menos extensas al tema en las monografías sobre empresas de Alonso, Erro y Arana (1998), Girona (1989), Ojeda (2000) y Sáez García (1999a). Los trabajos de González Portilla (1985) para el País Vasco y Ojeda (1985) para Asturias también tratan este tema. Sobre la cartelización del mercado en otros sectores de la economía española disponemos de un buen número de trabajos. Una relación detallada de los mismos en Comín y Martín Aceña (1996), pp. 93-98 y en Valdaliso (1999), p. 100.

3 La producción de lingote para la venta se concentró en las tres grandes empresas de Vizcaya (Altos Hornos de Bilbao, La Vizcaya y San Francisco), mientras que Altos Hornos y La Vizcaya controlaban la práctica totalidad de las ventas de palanquilla, llantón y carriles, y compartían la producción de chapas y estructurales con las fábricas asturianas (La Felguera y, en menor medida, Mieres). Los acuerdos relativos a estos productos en González Portilla (1985), pp. 191 y ss. 
alcanzase un equilibrio cooperativo que elevaba las ganancias de las empresas oligopolísticas ${ }^{4}$.

Frente a la sencillez del esquema que se obtiene del estudio de estos carteles, el mercado de los hierros y aceros comerciales ofrece una serie de características que lo hacen mucho más interesante para analizar el funcionamiento de los acuerdos colu$\operatorname{sivos}^{5}$. En primer lugar, se trataba de un producto elaborado por la práctica totalidad de las fábricas siderúrgicas. Por lo tanto, el sector de hierros comerciales se caracterizaba por la existencia de un mayor número de empresas (en torno a doce durante el periodo estudiado) y por una mayor dispersión geográfica. Por otra parte, hasta que se fundó Altos Hornos de Vizcaya (AHV) en 1901, no existió una empresa que ostentase una cuota de mercado lo suficientemente grande como para imponer sus condiciones a las demás. Estos factores dificultaban el logro de acuerdos, aumentaban los incentivos para transgredirlos y favorecían la aparición de empresas libres (freeriders). Las dificultades para detectar a los transgresores hicieron que cada nuevo acuerdo fuese incorporando mecanismos de control para garantizar el cumplimiento del mismo. Del estudio de los convenios relativos a hierros y aceros comerciales del periodo 1871-1907 se concluye que, como señala la economía industrial, la forma de evitar el incumplimiento de los acuerdos y la existencia de empresas libres constituyen el problema crucial de los carteles ${ }^{6}$. Por otra parte, se observa que la experiencia acumulada por los miembros del cártel permite prever mejor el resultado de los acuerdos colusivos y desarrollar mecanismos cada vez más complejos para garantizar el cumplimiento de los mismos.

Otro de los aspectos que se analiza en el trabajo es la influencia que la creciente cartelización del mercado siderúrgico pudo tener en el desarrollo económico del país, en particular en las décadas finales del siglo XIX y principios del XX. Algunos autores han considerado que las políticas proteccionistas y los acuerdos colusivos tuvieron como consecuencia una rigidez en la oferta de productos siderúrgicos muy superior a la que se dio en otros países desarrollados, lo que se tradujo en unos bajos niveles de producción y consumo ${ }^{7}$. Sin embargo, aceptando de antemano las consecuencias negativas que sobre la competitividad de las empresas acaban teniendo los mercados excesivamente protegidos y las prácticas restrictivas de la competencia, es

4 Sobre los factores que facilitan el logro y la viabilidad de los acuerdos colusivos, véase Stigler (1964).

5 El término hierros comerciales se aplicaba a los laminados de pequeña sección más comunes (redondos, cuadrados, flejes, llantas, pletinas, cortadillos para herraje, etc.) y a los martillados (rejas y calces para arados, llantas y ejes de carro, etc.). Quedaban fuera de dicha definición los planos de grandes dimensiones (chapas, llantón, etc.), los perfiles estructurales (vigas, viguetas y formas U), los carriles y sus accesorios, la palanquilla y los alambres.

6 Resúmenes sobre la teoría del oligopolio en Jacquemin y Slade (1989) y Segura (1993), pp. 152-177.

7 Esta idea ha sido expuesta por Fraile (1991) y Tortella (1994). El trabajo de Fraile ha sido objeto de crítica tanto por cuestiones metodológicas, Escudero (1999), como de fondo, Nadal y Sudrià (1993). 
conveniente analizar las relaciones entre las empresas siderúrgicas y sus clientes antes de señalar a los problemas de oferta como factor fundamental del atraso relativo de la economía española en este periodo ${ }^{8}$.

\section{Los primeros cárteles siderúrgicos (1871-1878)}

El primer acuerdo de precios del sector siderúrgico del que tenemos noticia tuvo lugar en 1871. Esto no significa que puedan descartarse convenios previos sobre precios o reparto de mercados entre las empresas del sector, pero lo cierto es que no tenemos constancia de la existencia de acuerdos estables que comprometiesen a la mayor parte de los productores con anterioridad a la citada fecha. La iniciativa para llegar a este primer convenio partió de las empresas asturianas, que, gracias a sus menores costes productivos lideraban el sector en ese momento ${ }^{9}$. En diciembre de 1871, Numa Guilhou y Pedro Duro, en representación de las fábricas de Mieres y la Felguera respectivamente, invitaron al resto de los siderúrgicos españoles a una reunión para tratar el tema de los precios de sus productos. No es casual que en esta fecha existiese un particular interés por llegar a acuerdos de precios. La década de los sesenta se había caracterizado por un aumento de la competencia en el sector y, como resultado de ello, por una notable reducción de los precios de los productos siderúrgicos -entre 1859 y 1869, los precios de los hierros laminados se redujeron un 33 por 100-, sin que por ello se produjese un aumento de la demanda (véase el Gráfico 1).

La reunión tuvo lugar en Madrid el 19 de diciembre de 1871, y a ella acudieron representantes de seis de las más importantes empresas siderúrgicas de España: junto a los ya citados Guilhou y Duro encontramos a representantes de El Carmen de Baracaldo (Vizcaya), Nuestra Señora del Remedio (Barcelona), Araya (Álava) y Beasain (Guipúzcoa). Los reunidos alcanzaron un acuerdo al que posteriormente se adhirieron Bolueta (Vizcaya), Hijos de Heredia (Málaga), Jáuregui de Astepe (Vizcaya), El Pedroso (Sevilla) y Fernando Campos (Vizcaya) ${ }^{10}$. De esta forma, el cártel agrupaba a la práctica totalidad de las instalaciones siderúrgicas modernas de España.

8 Se trata en definitiva de contribuir al debate sobre el papel de los empresarios en la economía española. Una síntesis del mismo en Comín y Martín Aceña (1996) y Valdaliso (1999).

9 Sobre la estructura de costes de las empresas siderúrgicas españolas durante el siglo XIX, véase Fernández de Pinedo (1985).

10 Aunque en la documentación no queda claro, es muy probable que la fábrica de Fernando Campos sea la de Santa Águeda de Castrejana, que posteriormente funcionaría bajo la razón social Aguirre y Cía. 


\section{GRÁFICO 1}

PRODUCCIÓN DE HIERRO DULCE Y ACERO (en Tm.) Y PRECIO DEL HIERRO EN BARRAS

$$
\text { (en pts./Qm.) }
$$

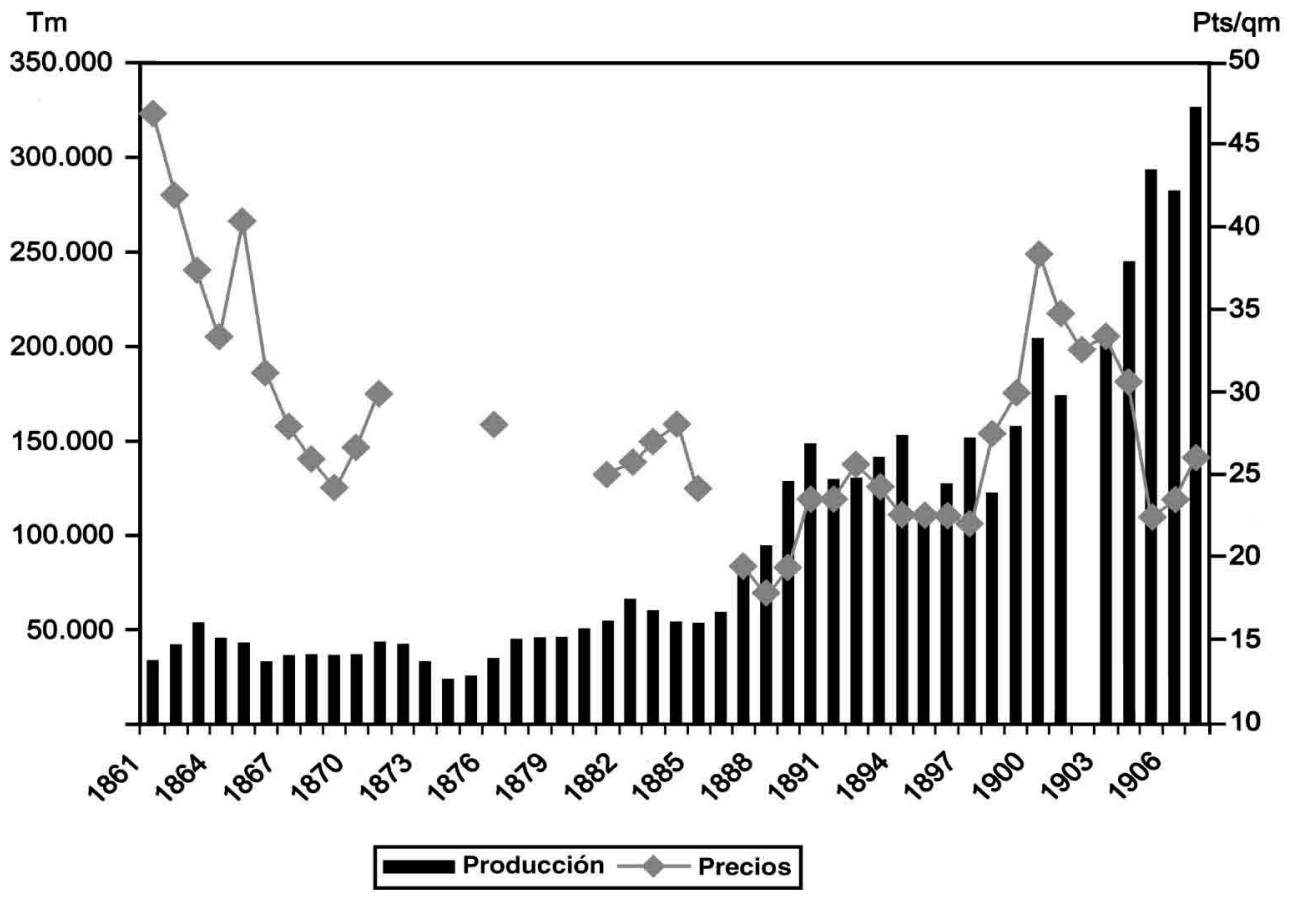

Fuentes: Producción de hierro dulce y acero en Estadística Minera y Metalúrgica de España. Los precios del hierro en barras han sido tomados de Coll (1994), p. 105 y coinciden en buena medida con los de los hierros comerciales facturados por la fábrica de Araya, recogidos en Sáez García (1999a), pp. 293-296.

Los reunidos acordaron que a partir de enero de 1872 subirían un 6 por 100 los precios de los hierros laminados y forjados que cada fábrica tenía en su tarifa11. Conviene destacar que no se trataba del establecimiento de una tarifa común, sino simplemente de un compromiso para recargar sus facturas en el citado porcentaje, manteniendo cada fabricante la tarifa que aplicaba a sus clientes, así como los descuentos que practicaba sobre la misma. Los convenidos no consideraron necesario 
adoptar ninguna medida para prevenir actitudes no cooperativas; únicamente se comprometieron a comunicarse sus tarifas indicando los descuentos y condiciones que ofrecían a los mejores clientes. Por otra parte, el convenio incluía también una cláusula en la que se nombraba un agente de los fabricantes en Madrid. Se pretendía con ello crear un lazo de unión permanente entre las empresas siderúrgicas, facilitando el mantenimiento de los compromisos o la modificación pactada de los mismos, y coordinar la defensa de los intereses del sector. Se sentaban así las bases para la actuación de los siderúrgicos como grupo de presión, que ejercería una influencia creciente sobre los poderes públicos.

El aumento de los precios no provocó un descenso de la demanda, por lo que los siderúrgicos incrementaron el recargo en sus tarifas. En junio de 1872 pasó del 6 al 10 por 100, en septiembre se elevó hasta el 20 por 100 y en marzo de 1873 hasta el 30 por 100, sin que ello supusiese establecer tarifas o condiciones de venta comunes. Quizás tampoco era necesario, ya que las deficientes infraestructuras portuarias y el escaso desarrollo de los ferrocarriles hacían que las fábricas más próximas a cada mercado tuvieran importantes ventajas gracias a los menores costes de transporte y a la mayor rapidez a la hora de servir los pedidos. No obstante, existían zonas en las que las mejores comunicaciones permitían una mayor competencia entre los productores de distintas regiones, como ocurría en el caso de Madrid ${ }^{12}$.

Los primeros problemas serios entre los firmantes del acuerdo surgieron en 1875. En febrero de dicho año, el agente de los fabricantes en Madrid planteaba la necesidad de revisar los precios a la baja, dada la reducción que estaban teniendo los hierros extranjeros como consecuencia de la depresión económica internacional. Para tratar de resolver el tema convocó a los firmantes del acuerdo a una reunión que tuvo lugar en Madrid el 21 de marzo de 1875. Sin embargo, los escasos resultados conseguidos en materia de precios, el continuado descenso en las ventas y las sospechas de incumplimiento de los acuerdos por parte de algunos asociados, hicieron que en junio los responsables de la fábrica de El Remedio de Barcelona abandonaran el cártel. A los catalanes siguieron las dos principales fábricas vizcaínas (Bolueta y El Carmen). Su ausencia hacía imposible seguir manteniendo los acuerdos, por lo que en enero de 1876 se disolvió el cártel siderúrgico ${ }^{13}$.

La ruptura del cártel provocó una abierta competencia y una importante caída de los precios $^{14}$, sin que por ello aumentasen las ventas, por lo que desde principios

12 La influencia de los costes de transporte en la distribución de las ventas de las empresas siderúrgicas españolas durante las décadas centrales del siglo XIX ha sido destacada por Carmona (1993) para Sargadelos, por Ojeda (1985) para las fábricas asturianas y por Sáez García (1999b) para Araya.

13 Correspondencia de Santibañes (agente de las fábricas en Madrid) con L. Urigoitia (Araya), $1872-1873$. ATHA. Fondo Ajuria, pendiente de organización (p. o., en adelante)

14 Entre principios de 1876 y finales de 1877, los precios de los hierros comerciales se redujeron alrededor de un 40 por 100. Sáez García (1999a), pp. 126-128. 
de 1877 hubo intentos de recomponer la "liga de precios", como gustaban de denominar los siderúrgicos a sus acuerdos. Sin embargo, éstos no fructificaron hasta que por iniciativa de Araya, Beasain y Bolueta, con el apoyo de La Felguera, se convocó una reunión en Madrid los días 7 y 8 de octubre de 1877, encuentro que permitió reconstruir el cártel. Los firmantes del acuerdo fueron los mismos que los de 1871 con las ausencias de Fernando Campos y El Pedroso y la incorporación de la sevillana Portilla, White y Cía ${ }^{15}$.

El acuerdo implicaba recuperar la figura del representante de las fábricas en Madrid para defender los intereses del sector y coordinar las actuaciones del cártel. Por lo que respecta a los precios, los fabricantes decidieron subirlos un 5 por 100 a partir del 15 de octubre, con las mismas condiciones establecidas en 1871. No obstante, en esta ocasión el objetivo era mucho más ambicioso. Conscientes de las dificultades que existían para controlar el cumplimiento de los acuerdos, se decidió que cada fabricante remitiera los precios de sus productos al representante para que éste distribuyera copias entre todos los asociados con el fin de fijar una tarifa común.

Un mes después de firmado el nuevo convenio surgieron sospechas sobre el cumplimiento del mismo, ya que, si bien las fábricas habían elevado sus facturas en un 5 por 100 según lo pactado, esto no tenía su correspondiente reflejo en el mercado, donde los almacenistas mantuvieron los precios anteriores. La falta de control sobre la distribución y los recelos sobre el cumplimiento del convenio hicieron que en diciembre de 1877 la barcelonesa El Remedio se separase del mismo. El resto de los fabricantes trataron de avanzar en el tema de la unificación de tarifas, confiando en que el logro de un acuerdo en este tema consiguiese mantener la unión entre los miembros del cártel. La existencia de una tarifa unificada constituía una base más sólida para el mismo, puesto que permitiría detectar con mayor facilidad las posibles infracciones del acuerdo de precios. En febrero, El Carmen de Baracaldo envió al agente en Madrid unas bases para unificar las tarifas de todas las fábricas, amenazando con separarse del acuerdo si no se aceptaban las mismas. La Felguera coincidía en la necesidad de llegar a un acuerdo sobre el tema, pero proponía sus propias bases ${ }^{16}$. La falta de entendimiento entre las dos principales empresas del sector provocó la separación de la fábrica de El Carmen de la liga de precios y, como consecuencia de ello, su ruptura el 18 de marzo de 1879. Esta ruptura ponía de manifiesto las dificultades que existían para establecer una tarifa común en ausencia de una empresa líder que impusiese sus condiciones al resto. Ni La Felguera, con una cuota de mercado en torno al 29 por 100, ni El Carmen, con un 18 por 100 del total, podían determinar los precios del mercado español.

15 Circulares a las fábricas asociadas. ATHA. Fondo Ajuria, p.o.

16 Las bases propuestas por la fábrica de El Carmen y la contrapropuesta de La Felguera en Sáez García (1997), pp. 13-16. 


\section{El acuerdo de 1889}

Durante la década de los ochenta, el sector siderúrgico español conoció importantes transformaciones. La fuerte competencia y la caída de los precios, provocadas por la ruptura del cártel, se iban a ver agravadas por la ampliación y modernización de la antigua fábrica de El Carmen, convertida ahora en Altos Hornos de Bilbao (AHB), y por la puesta en funcionamiento de La Vizcaya ${ }^{17}$. En un principio, esta última se dedicó en exclusiva a producir hierro colado para la venta, pero a finales de la década decidió instalar nuevos elementos productivos para transformar sus crecientes excedentes en aceros laminados, que, por otra parte, ofrecían la posibilidad de obtener mayores beneficios.

Aunque hubo algún intento previo de reconstruir el cártel, las iniciativas no prosperarían hasta que, en diciembre de 1888, la fábrica de Mieres inició los contactos con el resto de empresas. A pesar de que en un principio los responsables de AHB no se mostraron muy receptivos, los contactos continuaron y, a principios de marzo, el jefe administrativo de la empresa, Fernando Molina, se trasladó a Gijón para reunirse con los productores asturianos, alcanzando un acuerdo, que fue ratificado por el consejo de administración el 12 de marzo de $1889^{18}$.

Aunque el cártel quedó limitado a AHB y a las fábricas asturianas de La Felguera, Mieres y Moreda y Gijón, su capacidad para influir en el mercado era muy importante, puesto que estas empresas eran las de mayor tamaño del sector y las más eficientes en términos de costes de producción. Este acuerdo tenía al menos dos importantes diferencias con respecto a los firmados en la década de los setenta. En primer lugar, y por lo que respecta a los precios, por primera vez los mayores productores de laminados fijaban tarifas y descuentos comunes, frente a los simples recargos en factura de los convenios anteriores. En segundo lugar, el acuerdo de precios quedaba desligado de las actuaciones de tipo lobby, ya que no se conservaba la figura del representante de las fábricas en Madrid. Esto no implicaba que desapareciesen las acciones coordinadas de las empresas del sector para

17 Como se puede ver en el Gráfico 1, la tendencia a la baja de los precios se quebró únicamente entre 1880 y 1883, cuando algunas empresas siderúrgicas decidieron elevaciones de precios unilaterales, comunicándoselo al resto de los fabricantes, que optaron por aplicar subidas similares. Se trata, por lo tanto, de un caso típico de colusiones tácitas en las que no mediaba ningún acuerdo explícito entre las empresas oligopolísticas. Desde 1883, la competencia de los hierros extranjeros, que eran introducidos por los puertos de Levante y a través de Lisboa, provocó una fuerte reducción de las ventas y una caída de la producción de hierro dulce y acero. Sáez García (1999a), pp. 132-133. La trayectoria de la fábrica vizcaína de El Carmen y su transformación en Altos Hornos de Bilbao en Díaz Morlán (1999) y (2002).

18 Libro de Actas del Consejo de Administración de Altos Hornos de Bilbao (en adelante C.A. de AHB), 12-31889. Archivo Foral de Bizkaia (AFB). Fondo Altos Hornos de Vizcaya (AHV), libro 17. 
influir sobre el poder político. Por el contrario, éstas se intensificaron por medio de organizaciones que, al no depender de los acuerdos de precios, gozaron de una mayor estabilidad y cohesión interna ${ }^{19}$.

En los primeros días de julio de 1890, la fábrica de Mieres notificó su decisión de abandonar el acuerdo en el mes siguiente. El consejo de administración de AHB inició contactos con los productores asturianos para evitar la salida de Mieres, al tiempo que mantenía conversaciones con La Vizcaya, que se mostraba receptiva a la idea de entrar en el cártel ${ }^{20}$. Este aspecto era importante porque cuando se firmó el convenio en marzo de 1889, La Vizcaya fabricaba únicamente hierro colado, pero desde mayo de ese mismo año había puesto en funcionamiento tres hornos Martin-Siemens y un taller de laminación, lo que la convertía en uno de los principales productores de laminados de España ${ }^{21}$. Los contactos llevados a cabo entre empresas vizcaínas y asturianas dieron resultado y el primero de agosto se restablecía el acuerdo de precios, en el que se incluía también a La Vizcaya, manteniendo la tarifa común de 1889, pero rebajando los precios finales al aumentar del 6 al 12 por 100 los descuentos que se aplicaban sobre factura $^{22}$.

En junio de 1891, La Vizcaya denunció el acuerdo, lo que supuso la ruptura del mismo. En un mercado estrecho y con una fuerte competencia exterior, las nuevas unidades productivas sólo podían crecer a costa de otras fábricas. Si La Vizcaya quería aumentar su producción necesitaba ampliar su cuota de mercado y, para ello, tenía que ofrecer mejores condiciones que las empresas ya establecidas y, por lo tanto, necesitaba estar libre de compromisos a la hora de fijar sus precios y condiciones de venta. Éste era, sin duda, el motivo de su denuncia del convenio. En definitiva, el equilibrio cooperativo alcanzado por medio del acuerdo resultaba perjudicial para la expansión de la empresa, que para ampliar su cuota de mercado precisaba una situación de libre competencia que le permitiese aprovechar las ventajas de sus modernas instalaciones.

19 Hasta la creación de la Liga Vizcaína de Productores, la principal asociación para la defensa de los intereses siderúrgicos fue la Asociación de las Industrias Siderúrgicas, creada para participar en la información oral y escrita previa a la reforma arancelaria de 1890.

20 C.A. de AHB, 9 y 16 de julio de 1890. AFB. Fondo AHV, libro 18.

21 La producción de acero Martin-Siemens comenzó el 28 de mayo de 1889 y la laminación el 31 del mismo mes. En mayo de 1891 se empezó a fabricar hierro pudelado y en febrero de 1892 acero Bessemer. Anuario de la Minería, Metalurgia y Electricidad de España, 1896, p. 88.

22 C.A. de AHB, 29-7-1890. AFB. Fondo AHV, libro 18. Es importante señalar que entre 1889 y 1896, la práctica habitual a la hora de modificar los precios era aumentar o disminuir los descuentos sin alterar la tarifa vigente. 


\section{El acuerdo de $\mathbf{1 8 9 3}$}

Desde principios de 1892 hubo intentos de recomponer el cártel. La Felguera y AHB estaban de acuerdo en iniciar conversaciones para lograr un nuevo convenio de precios, pero sólo si incluía también a las fábricas pequeñas ${ }^{23}$. Por este motivo, invitaron a una reunión a los representantes de las mismas con el objetivo de alcanzar un nuevo acuerdo ${ }^{24}$. El encuentro tuvo lugar el día 25 de enero de 1893 en Bilbao y concluyó con la creación de un sindicato para la venta de hierros y aceros comerciales, al que se sumaron los principales productores siderúrgicos del país.

El nuevo convenio establecía una tarifa y unas condiciones de venta comunes, que incluían descuentos máximos del 13 por 100, más un 2 por 100 por pronto pago (dentro de los treinta días siguientes a la emisión de la factura) ${ }^{25}$. De la correspondencia entre los miembros del cártel se deduce que estos descuentos eran aplicados de forma general a todos sus clientes. No obstante, existía una discriminación de precios a favor de los grandes consumidores, ya que se establecía una bonificación de hasta un máximo del 5 por 100 para aquéllos que superasen las $150 \mathrm{Tm}$. de consumo anual.

Un aspecto fundamental que no se recogía en el acuerdo, pero que muy pronto fue objeto de estudio por parte del cártel, fue el de la exención o discriminación de precios a favor de determinadas actividades. La cuestión se planteó cuando, en marzo de 1894, La Vizcaya solicitó que en el convenio se incluyese un artículo adicional que declarase libres de las condiciones del mismo los pedidos de talleres y fábricas con destino al suministro de material para ferrocarriles que gozaban de franquicias o tarifas especiales reducidas y para construcciones destinadas a la exportación ${ }^{26}$. Estas peticiones fueron aceptadas por todos los asociados con el fin de evitar la llegada de materiales del extranjero cuando éstos podían ser suministrados a precios similares por las fábricas nacionales.

Las dos cuestiones que iban a generar mayores disensiones durante los tres años de vida del cártel fueron la política de precios y la actividad de las fábricas libres. Por lo que respecta al primer tema, en marzo de 1894, las fábricas asturianas propusieron una subida de precios. El objetivo era aprovechar al máximo el arancel y el coste de los fletes a la hora de fijar los precios en el interior, acompasándolos a los movimientos internacionales ${ }^{27}$. 
La subida no fue aprobada por los miembros del cártel debido a la oposición frontal de las principales empresas vizcaínas y de la Sociedad Material para Ferrocarriles. El motivo alegado para rechazar la propuesta era que el aumento de precios podía provocar una ruptura entre los siderúrgicos y las industrias derivadas en un momento que consideraban poco oportuno, dada la situación en la que se encontraba la cuestión arancelaria ${ }^{28}$. Sin embargo, la verdadera causa del rechazo quedó clara cuando, en noviembre de 1895, los fabricantes asturianos propusieron de nuevo subir los precios. Los responsables de La Vizcaya decidieron aceptar la propuesta de los asturianos a condición de que los talleres metalúrgicos de las provincias vascas "gozasen de la más completa libertad de precio y de la facultad de hacer sus compras donde tuviesen por conveniente" ${ }^{29}$. Lo mismo exigía AHB que incluía un listado de los talleres que debían quedar exentos (Tubos Forjados, Alambres del Cadagua, Pradera Hermanos y Compañía, Talleres de Zorroza y Sociedad Vasco-Belga) y proponía llegar a un acuerdo para eximir también del alza a los principales talleres de construcción de Barcelona (La Maquinista, Arsenal Civil, etc. $)^{30}$. Los intereses de los siderúrgicos vizcaínos en varias de las empresas citadas iban más allá de la simple relación comercial, puesto que algunos de los accionistas de AHB y La Vizcaya lo eran al tiempo de estas sociedades. Desde la entrada en vigor del arancel de 1891, los siderúrgicos vascos habían apoyado la creación de empresas capaces de generar una demanda para sus excedentes productivos, lo que acabó dando lugar a una cuasi-integración con las empresas metalúrgicas y de construcciones mecánicas, caracterizada por el suministro regular de materias primas en condiciones preferenciales ${ }^{31}$.

Resumiendo, desde 1893 se observa una actitud diferente en lo que se refiere a los precios del mercado interior. Los asturianos parecían dispuestos a aprovechar al máximo las ventajas que les brindaba el arancel para subir los precios y elevar sus

28 Carta de AHB a Bolueta, 30-3-1894. Archivo Histórico del Banco Bilbao Vizcaya Argentaria (BBVA). Fondo Bolueta, legajo 31.

29 C.A. de La Vizcaya, 12-11-1895. AFB. Fondo AHV, libro 8.

30 C.A. de AHB, 20-11-1895. AFB. Fondo AHV, libro 21.

31 Como ha señalado Fernández de Pinedo (1983) y (2001), la estrategia de los siderúrgicos vizcaínos de apoyar su crecimiento en la creación de empresas metalúrgicas, gracias a una política de sustitución de importaciones, quedó expresada en sus intervenciones ante la comisión para la reforma arancelaria de 1890. Las inversiones de los grupos empresariales vizcaínos en ambos sectores en Valdaliso (1988), pp. 13-20. El caso concreto de la familia Ybarra en Díaz Morlán (2002), pp. 161-170. Una breve síntesis, incluyendo las ventajas e inconvenientes de la cuasi-integración frente a la integración vertical, en Comín y Martín Aceña (1996). El trabajo de Cava (2000) sobre la Basconia muestra tanto este proceso de cuasi-integración entre siderurgia y metalurgia (capítulo 3), como los conflictos de intereses propios de este tipo de relaciones (pp. 149-150). Frente a la estrategia vizcaína, la principal fábrica del sector en Asturias optó desde principios del siglo XX por llevar a cabo un proceso típico de integración vertical, tanto hacia atrás (adquisición de sociedades mineras) como hacia delante (construcciones mecánicas). Ojeda (2000). 
beneficios. Por su parte, las grandes siderúrgicas vizcaínas contemplaban el asunto de otro modo. Su objetivo era ampliar el estrecho mercado interior y por este motivo trataban de evitar que las subidas de precios frustrasen el desarrollo de las empresas metalúrgicas y mecánicas con las que tenían un fuerte vínculo gracias a la existencia de consejeros y accionistas comunes.

A pesar de las diferencias entre asturianos y vizcaínos sobre la cuestión de los precios, el principal elemento de inestabilidad del cártel fue la actividad de las fábricas libres (free riders). El problema se planteó ya en las conversaciones previas a la firma del acuerdo de 1893. En ese momento, Bolueta se mostró conforme con la propuesta siempre y cuando participasen en la misma todos los fabricantes de hierros al carbón vegetal y, si no fuera así, solicitaba que el acuerdo se limitase a los hierros al cok, dejándose libres los precios de los elaborados al carbón vege$\mathrm{tal}^{32}$. Finalmente, Bolueta firmó el acuerdo de precios, si bien quedaron fuera dos de los principales fabricantes de hierros al carbón vegetal: Araya y Elgoibar.

Para contrarrestar la competencia de estas fábricas, el acuerdo incluyó una cláusula que declaraba libres los mercados de Ubidea, Ochandiano, Vitoria, Villaro, Oñate y Mondragón ${ }^{33}$. La medida no fue suficiente, ya que en julio de 1893, a petición de Vera de Bidasoa, los mercados exentos se ampliaron a Pamplona y San Sebastián. A principios de 1895, el problema, lejos de resolverse, se había agravado. La competencia de las fábricas libres era muy importante en "las clases especiales" (hierros al carbón vegetal), donde habían extendido sus mercados más allá de los límites del País Vasco y Navarra gracias a la concesión de bonificaciones a los pequeños clientes, bonificaciones que las empresas convenidas no podían realizar. Por este motivo, Astepe y Bolueta solicitaron al resto de los asociados permiso para conceder la bonificación anual del 5 por 100 - que se hacía, según el convenio, a los clientes que adquirieran más de $150 \mathrm{Tm}$., anuales- sin estar sujetos a ningún tonelaje $\mathrm{j}^{34}$. Frente a la postura de las fábricas pequeñas, AHB no estaba de acuerdo con que las bonificaciones se concediesen a todos los clientes al margen de su consumo anual, porque, aseguraba, esto perjudicaría mucho a los grandes consumidores. Sin embargo, se mostraba dispuesto a aceptar la propuesta de La Felguera de establecer una escala gradual de bonificaciones que permitiese obtener un descuento del 3 por 100 a aquéllos que tuviesen un consumo superior a $50 \mathrm{Tm}$. y del 4 por 100 para los que consumiesen más de 100, quedando reservado el 5 por 100 para los que adquiriesen más de 150 Tm., tal y como estipulaba el convenio ${ }^{35}$.

\footnotetext{
Alonso, Erro y Arana (1998), p. 160.

Alonso, Erro y Arana (1998), p. 160.

C.A. de La Vizcaya, 19-11-1895. AFB. Fondo AHV, libro 8.

C.A. de AHB, 26-3-1895. AFB. Fondo AHV, libro 20.
} 
La falta de acuerdo sobre el tema hizo que Bolueta y Astepe anunciasen su salida del cártel a finales de $1895^{36}$. Poco después, el consejo de La Vizcaya, sin llegar a denunciar el convenio, dio orden de vender "todo lo que se pudiera al mejor precio posible" ${ }^{\prime 37}$. A principios de 1896 fue La Felguera la que anunció su separación del cártel, lo que hizo que AHB estableciese contactos con representantes de las fábricas asturianas para recomponer el acuerdo. Como resultado de los mismos, se decidió invitar a todos los fabricantes a una reunión que tendría lugar el 25 de febrero de 1896 en Madrid.

\section{Renovación y ampliación del acuerdo de precios (27 de febrero de 1896)}

El orden del día de la reunión de Madrid incluía los siguientes puntos: a) reducir el mínimo de $150 \mathrm{Tm}$. para obtener la bonificación anual del 5 por 100, a propuesta de Bolueta; b) subir los precios un 10 por 100, a propuesta de La Felguera, y c) eximir de la subida del 10 por 100 a determinados talleres de transformación, a propuesta de La Vizcaya ${ }^{38}$. Se trataba, en definitiva, de buscar soluciones a los problemas que habían surgido en los meses anteriores y conseguir la adhesión de otras fábricas que habían mostrado interés por sumarse al cártel. El día 27 de febrero de 1896, los representantes de ocho empresas siderúrgicas (AHB, La Felguera, Elgoibar, Astepe, Sociedad Material para Ferrocarriles, Mieres, Moreda y Gijón y La Vizcaya) alcanzaban un nuevo acuerdo, al que pocos días después se sumaban Araya, Bolueta y Vera de Bidasoa que no habían acudido a la reunión. De esta forma, el nuevo convenio agrupaba a la práctica totalidad del sector ${ }^{39}$.

De nuevo se establecía una tarifa de precios común para los hierros y aceros comerciales, básicamente la del acuerdo de 1893, pero el descuento máximo pasaba del 13 al 2 por 100, lo que suponía aceptar la subida de precios propuesta por las fábricas de Asturias. Una novedad con respecto al acuerdo anterior es que los fabricantes de planos anchos y chapa, no incluidos en la tarifa común, se comprometían a fijar unos precios mínimos de venta para dichos productos ${ }^{40}$. Se comenzaba así un proceso de cartelización en un tipo de productos cuya elaboración estaba limitada a las cuatro grandes empresas del sector (AHB, La Vizcaya, La Felguera y Mieres).

\footnotetext{
36 C.A. de AHB, 20 -11-1895, AFB. Fondo AHV, libro 20, y 31-12-1895, libro 21.

37 C.A. de La Vizcaya, 19-11-1895. AFB. Fondo AHV, libro 8.

38 C.A. de AHB, 5-2-1896 y 20-2-1896. AFB. Fondo AHV, libro 21.

39 Carta de AHB a Bolueta, 17-2-1896. BBVA. Fondo Bolueta, legajo 40. Acuerdo de 27-2-1896 y cartas de J. Angoloti a Vda. de Urigoitia e hija (Araya), 28-2-1896 y 5-3-1896. ATHA. Fondo Ajuria, p.o.

40 Circular a las fábricas convenidas, 23-3-1896. ATHA. Fondo Ajuria, p.o.
} 
Por lo que respecta al controvertido tema de las bonificaciones de fin de año, se aceptó la idea de establecer una escala gradual que iba desde el 3,5 por 100 para aquellos que consumiesen menos de $50 \mathrm{Tm}$. anuales hasta un máximo del 7,5 por 100 para los que alcanzasen las $400^{41}$. Una novedad importante era que para fijar las bonificaciones a las que tenía derecho cada consumidor se tenía en cuenta la cantidad total que había adquirido durante el año a todas las fábricas convenidas. De este modo, los pequeños almacenistas podían obtener las bonificaciones sin necesidad de surtirse de una única fábrica, lo que sin duda beneficiaba a las más pequeñas y con menor variedad de productos ${ }^{42}$.

La principal novedad del acuerdo se encontraba en el artículo décimo, reflejo de la estrategia de las grandes empresas siderúrgicas vizcaínas de apoyar su crecimiento en la ampliación del mercado gracias al desarrollo del sector metalúrgico. Con vistas a lograr este objetivo, el acuerdo de 1896 establecía una discriminación de precios para algunas empresas, mientras que los pedidos de otras quedaban simplemente exentos de la tarifa y las condiciones establecidas en el convenio. A los talleres de construcciones mecánicas se les concedía un descuento único del 18 por 100 en todos los angulares y formas $\mathrm{T}$, dado que eran éstos los productos que en mayor cantidad consumían, sin hacerles ningún otro tipo de descuento ni bonificación, exceptuada la de pronto pago. Por otra parte, quedaban fuera del convenio los hierros servidos a las fábricas metalúrgicas ${ }^{43}$; es decir, las empresas siderúrgicas podían fijar los precios sin atenerse a la tarifa común, lo que suponía que este segmento del mercado no estaba cartelizado, sino que existía libre competencia. En el mismo sentido, el artículo undécimo declaraba libres del convenio "todos los suministros de materiales con destino a obras que gocen de régimen arancelario excepcional". En esta ocasión, se trataba de ampliar el acuerdo suscrito por los siderúrgicos en 1894, que eximía de las condiciones del convenio a los artículos destinados a las obras de los ferrocarriles y a todas las obras públicas que obtuviesen beneficios arancelarios del gobierno. El objetivo era que esta demanda no fuese abastecida por empresas extranjeras, dado que los fabricantes españoles eran capaces de igualar o mejorar los precios ofrecidos por las mismas gracias a las elevadas tarifas arancelarias establecidas desde principios de 1892.

\footnotetext{
Acuerdo de 27-2-1896. ATHA. Fondo Ajuria, p.o.

Acuerdo de 27-2-1896. ATHA. Fondo Ajuria, p.o.y C.A. de La Vizcaya, 3-3-1896. AFB. Fondo AHV, libro 8. Acuerdo de 27-2-1896. ATHA. Fondo Ajuria, p.o. Los miembros del cártel elaboraron una lista con las empresas metalúrgicas que podrían gozar de la exención de las condiciones generales: Iberia, Basconia, Tubos Forjados, Alambres del Cadagua, Pradera Hermanos y Compañía, Rodríguez Prendes y Compañía, La Flecha, A. Senil y Compañía y Sociedad para ferrocarriles y construcciones. Las fábricas de transformación que deseasen figurar en la lista deberían solicitarlo a los representantes del cártel, quienes, tras consultar a los asociados, tomarían una decisión al respecto. En el mes siguiente solicitaron y consiguieron su inclusión en la lista la Maquinista Terrestre y Marítima, de Barcelona, y los fabricantes de clavos y tachuelas Barbier Hermanos y Bouché, de Bilbao. Circular a las fábricas convenidas, 18-3-1896. ATHA. Fondo Ajuria, p.o.
} 
En resumen, la cartelización del mercado se limitaba en buena medida a la demanda más tradicional, hacia la que se orientaba la mayor parte del producto de las fábricas más pequeñas o con tecnología más obsoleta, mientras que la creciente demanda generada por el incipiente proceso de industrialización y modernización del país se encontraba libre de los precios y condiciones de venta del cártel, aunque protegida de la competencia extranjera por unas elevadas tarifas arancelarias.

Por lo que respecta a los mecanismos de control para el cumplimiento de los acuerdos, éstos seguían siendo muy limitados. En esta ocasión se constituyó una comisión central en Madrid compuesta por representantes de las fábricas con residencia en Madrid. El presidente de la misma era Federico Bayo, socio de La Felguera, y Joaquín Angoloti, consejero de AHB, su secretario. Las funciones de la comisión quedaban limitadas a transmitir las propuestas realizadas por los miembros del cártel y a tomar nota a fin de año de las ventas realizadas por cada fábrica para establecer las bonificaciones que correspondían a cada cliente ${ }^{44}$. El convenio no fijaba ninguna sanción contra los posibles transgresores. Sin embargo, el artículo octavo sí observaba acciones contra las fábricas libres. Así, para contrarrestar las actividades de éstas se declaraban libres algunos mercados del País Vasco y Navarra. No obstante, este artículo quedó sin efecto a los pocos días de firmarse el acuerdo, al incorporarse al mismo las tres fábricas ausentes (Araya, Bolueta y Vera de Bidasoa).

El convenio fue denunciado el 21 de mayo de 1896 por La Felguera, que alegó como motivo la caída de las ventas que venía sufriendo desde la firma del mismo. Tras dicha denuncia, el día 3 de junio se celebró una reunión en Madrid, en la que se declaró roto el acuerdo. No obstante, todos los presentes, excepto el representante de La Felguera, hicieron constar en acta que por su parte hubieran deseado continuar convenidos y que quedaban en situación de iniciar negociaciones para un nuevo arreglo ${ }^{45}$.

\section{La Delegación de Fabricantes de Hierro y Acero (1897-1904)}

Tras la ruptura del acuerdo, AHB decidió fijar descuentos que iban del 16 al 32 por $100^{46}$. Dado el peso de la empresa en el sector, esta decisión debió provocar una importante bajada en los precios de los hierros comerciales y, en menor medida, en las chapas y planos, sometidos a una menor competencia. En cualquier caso, un periodo prolongado de fuerte competencia no interesaba a ninguna de las fábricas,

\footnotetext{
44 Acuerdo de 27-2-1896. ATHA. Fondo Ajuria, p.o.

45 Circular a las fábricas convenidas, 3-6-1896. ATHA. Fondo Ajuria, p.o.

46 C.A. de AHB, 10-6-1896. AFB, Fondo AHV, libro 21.
} 
por lo que, en los primeros días de diciembre de 1896, AHB, de acuerdo con La Vizcaya, estableció contactos con varios fabricantes para proponerles una subida pactada de precios $^{47}$. El 9 de enero de 1897 envió al resto de fabricantes un "anteproyecto de bases para la formación de un Sindicato ó Asociación de todos los fabricantes de hierro de la Península". La totalidad de productores de hierro y acero mostraron su apoyo a la propuesta, por lo que se decidió convocar una reunión que se celebró el día 15 de febrero en la Cámara de Comercio de Bilbao ${ }^{48}$. De la citada reunión surgió el Sindicato de fabricantes de hierros y aceros comerciales (18 de febrero de 1897), en el que estaban integradas todas las fábricas de hierro y acero de España ${ }^{49}$. A los pocos días, a petición de $\mathrm{AHB}$, se decidió sustituir el término Sindicato por el de "Delegación de Fabricantes de hierro y acero", que sería desde entonces la denominación oficial del cártel.

Por lo que respecta a los precios, se fijaron una tarifa y unas condiciones de venta comunes. La tarifa era la misma de 1896, pero aplicando un descuento del 5 por 100. El espinoso tema de las bonificaciones anuales de acuerdo al consumo quedó zanjado en esta ocasión con el establecimiento de una escala gradual, que, al igual que en el acuerdo de 1896, tenía en cuenta la suma de lo adquirido por cada cliente a todas las empresas del cártel. Así, se establecían bonificaciones que iban desde el 1 por 100 para quienes consumiesen entre 50 y $100 \mathrm{Tm}$. hasta un máximo del 6 por 100 para los que tuviesen un consumo anual superior a $500 \mathrm{Tm}$.

La principal novedad de la Delegación respecto a los carteles anteriores era la mejora de los mecanismos de control para el cumplimiento del acuerdo. La existencia de precios y condiciones de venta comunes se había revelado insuficiente para detectar la existencia de transgresores. Por este motivo, en esta ocasión se recurrió al control de la producción. Así, los miembros del cártel comenzaron a trabajar para lograr "una distribución fija y permanente" del mercado. Se investigaron las ventas y los elementos productivos de las fábricas para fijar unas cuotas acordes a las posibilidades de cada una. Con este fin se estableció una oficina central en Madrid y se eligieron tres representantes de las fábricas con sueldo fijo. Su primera misión consistiría en comprobar las notas de las ventas realizadas por los firmantes del acuerdo en el último quinquenio, así como los elementos productivos con los que contaban ${ }^{50}$. Las cuotas establecidas son las que se pueden ver en el Cuadro 1. Las cuatro principales empresas del sector se repartían equitativamente dos tercios del mercado de hierros comerciales, quedando porcentajes mucho más reducidos para el resto de los asociados.

Carta de AHB a Bolueta, 11-12-1896. BBVA. Fondo Bolueta, legajo 40.

Circulares de AHB al resto de fabricantes, 9-1-1897, 4-2-1897 y 9-2-1897. ATHA. Fondo Ajuria, p.o.

A las once del acuerdo de 1896 se sumaba la fábrica vizcaína de Federico Echevarría.

Proyecto para la formación de un Sindicato de fabricantes de hierros. ATHA. Fondo Ajuria, p.o. La labor de inspección de los representantes queda confirmada por la relación de los pagos realizados en 1897, donde aparecen 2.613,55 pts. correspondientes a las dietas y gastos de sus viajes a Asturias, Araya, Barcelona, Vera y Bilbao. BBVA. Fondo Bolueta, legajo 44. 
CUADRO 1

CUOTAS DE MERCADO ASIGNADAS POR LA DELEGACIÓN DE FABRICANTES DE HIERRO Y ACERO A CADA UNA DE LAS EMPRESAS ASOCIADAS (en \%)

\begin{tabular}{lcc}
\hline Fábricas & Cuota $\mathbf{1 8 9 7 - 1 9 0 0}$ & Cuota desde junio de 1902 \\
\hline Altos Hornos de Bilbao & 16,27 & 31,00 \\
La Vizcaya & 16,27 & 16,35 \\
La Felguera (Duro y Cía) & 16,27 & 16,35 \\
Mieres & 16,27 & 7,60 \\
Moreda y Gijón & 6,62 & 4,50 \\
Material para ff.cc. y construc. & 5,22 & 5,52 \\
Elgoibar (Hijos de R. García) & 5,02 & 5,47 \\
Araya (Vda. de Urigoitia) & 4,96 & 5,13 \\
Vera de Bidasoa & 4,63 & 3,50 \\
Santa Ana de Bolueta & 4,34 & 3,33 \\
Astepe (Hijos de Jáuregui) & 2,61 & 1,25 \\
Federico Echevarría & 1,52 & \\
\hline
\end{tabular}

Fuentes: Circulares de la Delegación. BBVA, Fondo Bolueta, legajos 44 y 78; y ATHA, Fondo Ajuria, p.o.

La labor de los representantes de la oficina central de Madrid no finalizó con la asignación de las cuotas. Ellos iban a ser los encargados de "hacer cumplir religiosamente todas las bases del Sindicato". Para ello, se les facultaba para realizar viajes para investigar si se cumplían los términos del convenio. Además, se encargarían de controlar las ventas realizando resúmenes mensuales y anuales de las mismas, que servirían para establecer las bonificaciones de fin de año. Para elaborarlos, las fábricas tenían la obligación de pasar diariamente una nota detallada de sus ventas y duplicados de sus facturas, indicando el tipo de hierros y el precio de venta ${ }^{51}$.

Los mecanismos para vigilar el cumplimiento del acuerdo fueron acompañados de sanciones contra los transgresores. En 1896, las fábricas las habían considerado innecesarias, "porque de la buena fe de todos y más aun del interés que todos han de tener en respetar este acuerdo, debe esperarse lógicamente que ninguno ha de

51 Acuerdo de 27-2-1896. ATHA. Fondo Ajuria, p.o. 
faltar á lo aquí tratado"52. En esta ocasión se prefirió confiar menos en la buena fe y se fijaron penalizaciones de 45 pts. por cada tonelada vendida de más, y compensaciones de 20 pts por cada tonelada de menos ${ }^{53}$. Se trataba así de garantizar que las ventas no excedieran las cuotas fijadas. Sin embargo, estas cuotas fueron modificadas en 1902, dado que algunos productores solicitaron un aumento de su participación aduciendo la trayectoria de las ventas del periodo 1897-1901. La redistribución afectó sobre todo a las fábricas pequeñas, reduciendo la cuota de mercado de aquéllas que sistemáticamente vendían menos de lo que les correspondía (Bolueta, Echevarría y la Material) y en beneficio de las que año tras año eran multadas por superar sus ventas el porcentaje asignado (Astepe, Moreda y Gijón, Araya, Elgoibar y Bidasoa).

En cuanto a las exenciones de las condiciones del cártel para determinados clientes, éstas fueron en principio mucho más restringidas que en el acuerdo anterior. Los redondos tipo fer-machine destinados a la fabricación de alambres y los flejes y llantas para elaborar tubos forjados quedaban libres de las condiciones del cártel ${ }^{54}$. La Delegación era la que decidía qué sociedades podían acogerse a los beneficios de dicha base.

A pesar de que ésta era la única exención a la que se hacía alusión en las bases del convenio, en los años siguientes se fueron adoptando resoluciones que suponían una discriminación de precios favorable a las empresas metalúrgicas y de construcciones mecánicas. Así, el 20 de abril de 1898, a propuesta de la Sociedad Material para Ferrocarriles, se excluyeron de la subida de precios acordada en dicha fecha los ángulos y $\mathrm{T}$ de más de $44 \mathrm{~mm}$. (de gran consumo en las industrias mecánicas). Además, se autorizó a las fábricas para que pudieran bajar los precios de dichos productos "al límite que considerasen oportuno" en suministros importantes a las sociedades Maquinista Terrestre y Marítima, Arsenal Civil y otros talleres de construcciones mecánicas. Estos pedidos debían ser declarados a la Delegación, que los distribuiría de forma proporcional entre los asociados interesados en tomar parte en el suministro ${ }^{55}$.

En el mismo sentido apuntaba una nueva circular de mayo de 1898 en la que se comunicaba la baja de 2 pts., en $100 \mathrm{Kg}$., de los precios de la tarifa vigente para los

52 Proyecto para la formación de un Sindicato de fabricantes de hierros. ATHA. Fondo Ajuria, p.o.

53 La diferencia entre sanciones y compensaciones supuso en 1897 un saldo de 87.650 pts., que permitieron cubrir los gastos de la delegación de ese año, equivalente a 28.061 pts., y repartir las 59.589 restantes entre los socios en proporción a su participación. Desde 1900 se redujeron las sanciones a 30 pts. por Tm., manteniéndose las 20 pts. de compensación (acuerdo alcanzado en la reunión de las fábricas del día 28-10-1899), aunque en 1904 se decidió volver a aumentarlas a 45 pts. por Tm. C.A. de AHB, sesión del 4-11-1899. AFB. Fondo AHV, libro 24 y circular de la Delegación, 10-10-1904. BBVA. Fondo Bolueta, legajo 84.

54 Proyecto para la formación de un Sindicato de fabricantes de hierros. ATHA. Fondo Ajuria, p.o.

55 Circular de la Delegación, 20-4-1898. BBVA. Fondo Bolueta, legajo 45. 
hierros facturados a los fabricantes de tornillos, tuercas y remaches, además del descuento y bonificación máximos que se conceden a los mejores clientes ${ }^{56}$.

La última concesión de este tipo de la que tenemos noticia se produjo en junio de 1903, cuando Altos Hornos de Vizcaya propuso que se autorizase a los asociados a acudir a los concursos para el abastecimiento de las compañías ferroviarias "con libertad de precios" 57 . La petición venía motivada porque en un concurso convocado por MZA para la compra de $400 \mathrm{Tm}$. de hierros comerciales fue aceptada la propuesta de la Sociedad Sambre et Moselle, con un precio 2,96 pts. más bajo que el ofrecido por AHV, cuya oferta se hizo según la tarifa de la Delegación. La empresa vizcaína trataba, por lo tanto, de evitar que la falta de flexibilidad para el suministro de grandes pedidos hiciese que éstos fuesen a parar al extranjero, dado que las compañ́as de ferrocarriles invitaban siempre a la industria extranjera a participar en los concursos de suministro que convocaban. La propuesta de AHV fue aprobada por unanimidad, aunque quedó limitada a las grandes compañías, esto es, Norte, MZA, Andaluces y Oeste de España ${ }^{58}$.

La política de discriminación de precios practicada durante estos años no permitió en todos los casos compensar las fuertes subidas experimentadas por los productos siderúrgicos entre 1897 y 1900. En este periodo, los precios de los hierros y aceros comerciales aumentaron más de un 50 por 100 (véase el Gráfico 1). Esta situación provocó, desde fechas tempranas, las protestas de las empresas metalúrgicas y de construcciones mecánicas, en particular de las radicadas en Cataluña, que a principios de 1899 solicitaron por medio de la Liga de Defensa Industrial y Comercial y del Fomento del Trabajo Nacional una importante rebaja en los precios para "armonizar" los intereses de las industrias siderúrgicas y de los consumidores de sus productos $^{59}$. Las diferencias entre unos y otros continuaron durante los primeros años del siglo XX, a pesar de que, desde principios de 1901, la Delegación bajó los precios y desde abril de 1903 se estableció una nueva tarifa en la que se reducían los de los perfiles más gruesos (los más demandados por las empresas de construcciones mecánicas $)^{60}$.

Una de las cuestiones que generó mayores problemas al cártel durante su existencia fue la actividad de las empresas que actuaban al margen del mismo y, sobre todo, la reapertura de Altos Hornos de Málaga ${ }^{61}$. Desde el 1 de junio de 1898 se estableció un "modus vivendi" con la empresa malagueña, que suponía que ésta se

\footnotetext{
56 Circular de la Delegación, 13-5-1898. BBVA. Fondo Bolueta, legajo 47.

57 C.A. de AHV, 29-5-1903. AFB. Fondo AHV, libro 72.

58 Circular de la Delegación, 5-6-1903 y 19-6-1903. BBVA. Fondo Bolueta, legajo 77.

59 Cartas remitidas por la Delegación en febrero de 1899. BBVA. Fondo Bolueta, legajo 52.

60 Circular de la Delegación, 31-1-1903. BBVA. Fondo Bolueta, legajo 77.

61 La trayectoria de la fábrica malagueña desde sus orígenes en Nadal (1992).
} 


\section{CUADRO 2}

VENTAS DE HIERROS COMERCIALES DE LA DELEGACIÓN Y DE LA FÁBRICA DE MÁLAGA (en TM.)

\begin{tabular}{lcc}
\hline Año & $\begin{array}{c}\text { Ventas del cártel } \\
\text { (sin Málaga) }\end{array}$ & Ventas de Málaga \\
\hline 1897 & 52.927 & \\
1898 & 54.565 & 2.459 \\
1899 & 57.364 & 6.565 \\
1900 & 63.992 & 6.563 \\
1901 & 55.172 & 8.780 \\
1902 & 62.653 & 9.035 \\
1903 & 58.433 & 12.483 \\
1904 & 44.129 & 9.527 \\
\hline
\end{tabular}

Notas: En las cifras de 1904 faltan 5.727 Tm., de las cuales no se específica qué cantidad corresponde a Málaga y cuál al cártel.

Fuentes: Las ventas de 1897, 1899, 1900 y 1904 de la Delegación han sido obtenidas de las circulares remitidas por la misma a sus asociados, al igual que los datos de ventas de Málaga de 1904. BBVA, Fondo Bolueta, legajos 44 y 78; y ATHA, Fondo Ajuria, p.o. El resto de los datos proceden de González Portilla (1985), p. 227, aunque han sido corregidos por observarse importantes errores en las sumas totales en algunos años.

adhería a la tarifa y a las condiciones de venta comunes (incluido el sistema de bonificaciones), aunque la falta de acuerdo impidió asignarle una cuota fija como al resto de las fábricas ${ }^{62}$. La principal dificultad estribaba en que los representantes de Málaga pretendían establecer su porcentaje de participación tomando como base su capacidad productiva, cuando éste no había sido el criterio aplicado al resto de los miembros del cártel, que, por lo general, no trabajaban al máximo de su capacidad ${ }^{63}$. A pesar de los esfuerzos del cártel para llegar a un acuerdo, nunca se logró la plena integración de Altos Hornos de Málaga, lo que le permitió seguir ganando cuota de mercado, como se puede ver en el Cuadro 2.

Otra de las fábricas que había comenzado a producir aceros comerciales al calor de los importantes beneficios generados por el cártel era la vizcaína de San Francisco, que en 1903 puso en funcionamiento un horno Martin-Siemens para transformar

\footnotetext{
62 Circular de la Delegación, 28-5-1898. BBVA. Fondo Bolueta, legajo 47.

63 Circular de la Delegación, 3-10-1899. BBVA. Fondo Bolueta, legajo 51.
} 
parte de los excedentes de lingote de sus altos hornos. A diferencia de Málaga, trató desde el primer momento de llegar a un acuerdo con la Delegación. Así, el 18 de marzo de 1904, un delegado de la San Francisco, Blas Alzaga, visitó a los representantes del cártel exponiendo que la fábrica había comenzado la producción de laminados y había firmado contratos con varios almacenistas por una cantidad de 5.000 Tm. a precios inferiores a los de la Delegación, y proponía llegar a un acuerdo para evitar una guerra de precios. Las condiciones propuestas por la San Francisco eran bastante razonables y no debían plantear problemas para su aceptación: pedía que la cuota que se le asignase se estableciese en correspondencia con sus medios de producción comparados con los del resto de las fábricas y ofrecía declarar los contratos que tenía hechos a bajo precio para distribuirlos entre los miembros del cártel ${ }^{64}$. Aunque existía unanimidad en aceptar a la San Francisco, su entrada quedó pospuesta hasta que se hubiese tomado una decisión sobre la reforma de las bases del cártel que se estaba debatiendo en ese momento ${ }^{65}$.

La aparición de nuevas unidades productivas y el aumento de las importaciones habían provocado una rebaja de los precios del cártel, pasando el precio base de los laminados de 40 pts. a principios de 1900 a 29 pts. cuatro años después. A pesar de ello, no fue posible evitar que las fábricas libres ampliasen su cuota de mercado a costa de los miembros del cártel, lo que generó también una mayor competencia entre los mismos para tratar de aumentar sus ventas. Ante esta situación, la Delegación convocó a las fábricas a una reunión el día 5 de marzo de 1904 con el fin de estudiar una serie de propuestas dirigidas a resolver estos problemas ${ }^{66}$. En la misma se decidió una importante rebaja en los precios de los hierros comerciales más comunes, se aumentaron las sanciones para los fabricantes cuyas ventas superasen las cuotas asignadas y se instó a los representantes del cártel para que elaborasen un proyecto de nuevo convenio que debería ser estudiado por todos en una nueva reunión ${ }^{67}$.

Los representantes de la Delegación cumplieron con el encargo. En los primeros días de octubre de 1904, tras haberse entrevistado con los miembros de la asociación y constatar que no existía unanimidad sobre los medios que se debían utilizar para "corregir las deficiencias notadas" en el funcionamiento del convenio, enviaron a las fábricas un informe señalando las principales causas de los problemas surgidos, las posibles soluciones y los artículos que habrían de servir de base a un nuevo convenio. Se señalaba como causa de los problemas que afectaban al sector el insuficiente

\footnotetext{
64 Circular de la Delegación, 18-3-1904. BBVA. Fondo Bolueta, legajo 87.

65 Circular de la Delegación, 10-10-1904. BBVA. Fondo Bolueta, legajo 84.

66 Circular de la Delegación, 19-2-1904. BBVA. Fondo Bolueta, legajo 87.

67 Circular de la Delegación, 13-3-1904. BBVA. Fondo Bolueta, legajo 87.
} 
consumo de hierros comerciales frente a la creciente capacidad productiva de las fábricas establecidas, lo que, en épocas de crisis, provocaba la competencia entre los miembros del cártel, dado que las sanciones establecidas no eran lo suficientemente elevadas. Por este motivo, la Delegación concluía que cualquier solución al problema pasaba por prescindir del sistema de venta libre, sustituyéndolo por una centralización de las ventas, es decir, por el reparto de las mismas por medio de una oficina de ventas ${ }^{68}$.

A pesar de la oposición de algunas fábricas a esta solución, los representantes de la Delegación propusieron un nuevo convenio que tuviese como base fundamental dicho sistema. De esta forma, el propio cártel ejercería un fuerte control sobre la distribución dificultando el fraude. El control de la distribución se realizaría también por medio de los grandes almacenistas, ofreciéndoles elevadas bonificaciones a cambio de "ejercer una determinada vigilancia". Además, se proponía un sistema de inspección para controlar todas las ventas y asegurarse de que no se sirvieran más pedidos que los repartidos por la oficina central. Con este fin se obligaría a las fábricas a declarar todas sus ventas, fuesen o no de los productos cartelizados, para facilitar la comprobación del peso de los hierros expedidos por cada una ${ }^{69}$.

Para examinar la propuesta se convocó a todos los asociados a una reunión el día 24 de octubre de 1904 en las oficinas de la Delegación en Madrid. AHV llegó a la reunión con las ideas muy claras. Su representante, José Luis de Goyoaga, declaró al comenzar la reunión que consideraba roto el acuerdo y que AHV había decidido no participar en ningún nuevo convenio, ni en la prórroga o modificación del existente, "teniendo en cuenta los resultados producidos por el convenio vigente, (...) la forma en que el mismo ha sido cumplido y las pretensiones de las nuevas fábricas establecidas $^{\prime 70}$.

\section{La Unión Siderúrgica y la creación de la Central Siderúrgica}

Tras la separación de AHV, los demás fabricantes, liderados por Duro-Felguera, que se vio especialmente afectada por la ruptura del sindicato debido a las ambiciosas inversiones que venía realizando desde principios de siglo ${ }^{71}$, trataron de continuar con los acuerdos de precios y fundaron la Unión Siderúrgica. La debilidad de la nueva asociación era evidente, no sólo por la ausencia de AHV, sino también por la

\footnotetext{
Circular de la Delegación, 10-10-1904. BBVA. Fondo Bolueta, legajo 84.

Circular de la Delegación, 10-10-1904. BBVA. Fondo Bolueta, legajo 84

C.A. de AHV, 21-10-1904. AFB. Fondo AHV, libro 74.

Ojeda (1985), pp. 286 y ss.
} 
de otras fábricas que habían estado en el cártel anterior (Moreda y Gijón y Sociedad Material para Ferrocarriles), así como de San Francisco y Altos Hornos de Málaga. Por este motivo, la vida de la asociación fue corta. A finales de enero de 1906, las fábricas de Elgoibar, Vera de Bidasoa, Bolueta y Astepe comunicaban su separación de la misma, por lo que pocos días después, La Felguera, Mieres, Moreda y Gijón (que acababa de incorporarse a la Unión) y Araya decidieron que con un número tan reducido de asociados no tenía sentido seguir adelante ${ }^{72}$.

Durante el año de vida de la Unión Siderúrgica quedó claro que el "árbitro de la cuestión" era AHV. ${ }^{73}$ Conscientes de ello, los miembros de la unión simplemente se comprometían a adoptar unos precios mínimos y unas condiciones de venta comunes, siguiendo la política de precios de la empresa vizcaína. Así se demostró cuando, a principios de 1905, AHV llevó a cabo una rebaja en sus tarifas, que fue seguida por el resto de las fábricas, con lo que los precios de los productos siderúrgicos se situaron en niveles similares a los de 1897. Igualmente, cuando en enero de 1906, AHV estableció una nueva tarifa con una nueva clasificación de algunos productos, los delegados de la Unión Siderúrgica consideraron innecesario consultar a las fábricas sobre el tema, simplemente les enviaron la nueva tarifa de la empresa vizcaína y les invitaron a "circular tarifas análogas"74. En definitiva, los asociados aceptaron desde el principio su posición de debilidad ante la empresa líder del sector y se limitaron a seguir la política de precios marcada por la misma.

La importante caída que sufrieron los precios desde la ruptura del cártel (véase el Gráfico 1) hizo que buena parte de las empresas siderúrgicas atravesasen importantes dificultades en los dos años siguientes. Por este motivo, desde finales de 1905, representantes de la Unión Siderúrgica establecieron contactos con AHV para tratar de recomponer el cártel. Tras varios fracasos, todas las fábricas dedicadas a la elaboración de hierros y aceros laminados, con la única excepción de Araya, firmaron el 16 de diciembre de 1906 el convenio por el que nacía la Central Siderúrgica, el cártel más estable y longevo del sector.

El extenso texto del acuerdo suponía un esfuerzo por recoger toda la experiencia adquirida durante las décadas anteriores y, en particular, la de los años de funcionamiento de la Delegación. El nuevo cártel agrupaba prácticamente todos los productos laminados: comerciales, chapas, planos, vigas y formas $\mathrm{U}$, todos ellos con tarifa y condiciones de venta comunes y con discriminación de precios a favor de las fábricas metalúrgicas y los grandes consumidores. Pero la principal novedad, y piedra angular del nuevo convenio, era la central de ventas, establecida en unos términos

72 Circulares de la Unión Siderúrgica, 4-2-1906 y 19-2-1906. BBVA. Fondo Bolueta, legajo 98.

73 Revista Minera Metalúrgica y de Ingeniería (1906), p. 445.

74 Como señalaba la propia circular: "la base de nuestro convenio [es] aceptar los precios de las fábricas importantes que están fuera de ella...". Circular de la Unión Siderúrgica, 3-1-1906. BBVA. Fondo Bolueta, legajo 92. 
muy parecidos a los que en su momento propusieron los representantes de la Delegación. El otro aspecto destacable del nuevo cártel fue el fuerte control ejercido por la empresa líder del sector. El liderazgo de AHV se observaba no sólo en la distribución de las cuotas asignadas para cada tipo de productos (49 por 100 en comerciales, 45 por 100 en vigas y hierros en U y 56,40 por 100 en chapas), sino también en el poder que el reglamento del nuevo convenio le otorgaba en la toma de decisiones. En todos los convenios anteriores, las decisiones se tomaban con la mayoría de los votos de los asociados, correspondiendo un voto a cada uno de ellos, sin tener en cuenta su mayor o menor importancia o cuota de ventas asignada. Por el contrario, en el reglamento de la Central Siderúrgica se establecía que los votos de cada una de las empresas tendrían tanto valor como su porcentaje de participación en el cártel, esto es, en la práctica el voto de AHV valía tanto como los del resto de los $\operatorname{asociados}^{75}$.

\section{Conclusiones}

La trayectoria de los acuerdos colusivos en la siderurgia española entre 1871 y 1907 demuestra que los procesos de cartelización del mercado son mucho más complejos de lo que en ocasiones se supone. El esquema tradicional afirma que, dadas unas determinadas condiciones como reserva del mercado interior, concentración geográfica, debilidad del poder político que le hace vulnerable ante las presiones del poder económico, etc., resulta sencilla la cartelización del mercado, permitiendo a las empresas alcanzar elevados beneficios a costa de los consumidores. El esquema puede resultar más o menos válido para el momento en el que existe una larga tradición de acuerdos colusivos y una consolidación de los mismos, pero debe ser objeto de importantes matizaciones en lo que se refiere al proceso de formación de los carteles, al alcance que los acuerdos tienen en el mercado nacional y a las consecuencias de los mismos en el desarrollo de las empresas metalúrgicas y, por lo tanto, en el proceso de industrialización. Los aspectos más relevantes de los acuerdos siderúrgicos en España se han recogido en el apéndice que aparece al final del texto y se resumen en las siguientes páginas.

Por lo que respecta a la formación de los carteles, éstos no surgen simplemente como consecuencia de un marco institucional que en un determinado momento favorece su aparición y la imposición de sus condiciones en el mercado nacional. Por 
el contrario, se trata de un proceso lento en el que la experiencia adquirida por los oligopolistas en acuerdos anteriores les lleva a tomar medidas o crear mecanismos que garanticen el cumplimiento de las reglas del cártel. Según la teoría económica tradicional sobre el tema, el problema fundamental que se plantea en los acuerdos colusivos es el reparto del mercado y la detección de los transgresores. Sin embargo, del análisis de los acuerdos alcanzados por los siderúrgicos entre 1871 y 1907 se deduce que, como afirma la economía industrial, la cuestión fundamental es evitar que se produzcan incumplimientos del acuerdo por parte de los miembros del cártel y crear mecanismos que impidan la actuación de los free riders (fábricas libres). Como se ha visto en las páginas anteriores, la tarifa y condiciones de venta comunes, las cuotas fijas de reparto del mercado y, por último, la centralización de las ventas, constituyen pasos sucesivos para tratar de garantizar el cumplimiento de los acuerdos, evitando la competencia entre los miembros del cártel y dificultando la actuación de los free riders, que tratan de beneficiarse de la situación creada sin participar de las restricciones impuestas a los convenidos. Cada nuevo mecanismo de control implica una mejora organizativa, pasando de un agente a sueldo que coordine las acciones del cártel a una estructura mucho más compleja con oficinas propias y personal contratado que permita recibir los pedidos y repartirlos entre las empresas. Por el contrario, las sanciones a los transgresores y las medidas contra las fábricas libres merecen, por lo general, una menor atención. Esto es debido a que, por un lado, resulta difícil desarrollar mecanismos adecuados que permitan actuar contra los free riders (declarar determinados mercados exentos de las condiciones del cártel o rebajas de precios) sin dañar los intereses de las empresas convenidas, y, por otro, las sanciones económicas a los transgresores no incentivan el cumplimiento riguroso de los acuerdos, ya que, en ocasiones, los beneficios obtenidos de la transgresión son superiores a las multas impuestas.

Por otra parte, se observa que la estabilidad del acuerdo viene determinada en buena medida por la existencia de una empresa líder capaz de imponer sus condiciones al resto de los oligopolistas. En el periodo analizado sólo se puede hablar de empresa líder a partir de 1901 con la aparición de Altos Hornos de Vizcaya, que constituye un caso típico tanto por su amplia cuota de mercado (en torno al 50 por 100 de la producción de aceros laminados), como por su capacidad para fijar un precio que es aceptado por el resto de las empresas aún en condiciones de competencia oligopolística (como ocurrió entre 1905 y 1907), gracias a unos costes marginales inferiores a los del resto del sector. De esta forma, la empresa líder puede actuar contra los free riders y los transgresores -aproximando los precios a sus costes marginales y eliminando a los menos competitivos- $y$, una vez simplificado el mapa siderúrgico, establecer sus condiciones a través de un nuevo acuerdo en el que impone sus condiciones al resto de las empresas (acuerdo de 1907). 
Por lo que respecta al alcance de los acuerdos, se ha visto que la cartelización del mercado siderúrgico entre 1871 y 1907 mostró importantes limitaciones, como lo demuestran las reiteradas rupturas de los acuerdos y la entrada de nuevos competidores. Estas limitaciones tuvieron su origen en la rigidez del mercado interior y en la falta de elasticidad de la demanda, que ocasionaron efectos antagónicos en la cartelización del sector. Por un lado, el lento crecimiento -incluso estancamiento en buena parte del siglo XIX- de la demanda interior alentó tempranamente a los siderúrgicos a alcanzar acuerdos para evitar los efectos ruinosos de la competencia. Por otro lado, la estrechez del mercado interior hacía que la aparición de nuevos competidores -Altos Hornos de Málaga y San Francisco- o la ampliación de la actividad de las empresas existentes -caso de Altos Hornos de Bilbao en los años ochenta o La Vizcaya en los noventa- tuviese lugar siempre a costa de otros productores y acabase provocando la ruptura de los acuerdos.

Para finalizar es importante destacar que los siderúrgicos, tanto en los momentos de cartelización del mercado como en los de competencia oligopolística, realizaron una política de discriminación de precios que favorecía a las empresas transformadoras y a los grandes consumidores (almacenistas de hierros) frente a los pequeños. En ocasiones se vieron obligados a eximir de las condiciones del cártel a algunos sectores para que las grandes empresas tuviesen libertad para luchar contra la competencia extranjera en el abastecimiento de las obras públicas, los ferrocarriles, las construcciones mecánicas y la metalurgia. Esto no quiere decir que no existiesen roces entre las empresas mecánicas y las siderúrgicas, dado que, por lo general, estas últimas trataban de aprovechar al máximo las ventajas que les ofrecían los elevados aranceles establecidos desde enero de 1892. No obstante, a la hora de valorar la contribución de la siderurgia española al desarrollo económico español durante este periodo, no parece conveniente sacar conclusiones apoyándose únicamente en la existencia de carteles o en series de precios obtenidas de las tarifas o de las publicaciones periódicas de la época sin tener en cuenta las condiciones específicas concedidas a las industrias metalúrgicas y de construcciones mecánicas en cada momento, que diferían bastante de las aplicadas a otros sectores de actividad. En el caso de los productos que quedaron fuera del cártel, sólo el análisis de los contratos privados entre consumidores y empresas suministradoras permitirán hacer una comparación adecuada entre los precios internacionales y los ofertados por los siderúrgicos españoles. 


\section{Bibliografía}

ALONSO, Eduardo J., ERRO, Carmen y ARANA, Ignacio (1998): Santa Ana de Bolueta, 1841-1998, Bilbao, SPRI.

CARMONA, Joám (1993): "Sargadelos en la historia de la siderurgia española", Revista de Historia Industrial, 3, pp. 11-40.

CAVA, María Jesús (2000): Basconia, S.A. (1892-1969). Historia, tecnología y empresa, Bilbao.

COLL, Sebastián (1994): "Precios y valores de la producción minera y metalúrgica española 1868-1935. Un intento de rectificación de las cifras oficiales", Áreas, 16, pp. 95-129.

COMÍN, Francisco y MARTÍN ACEÑA, Pablo (1996): "Rasgos históricos de las empresas en España. Un panorama", Revista de Economía Aplicada, 12, pp. 75-123.

DÍAZ MORLÁN, Pablo (1999): Los Ybarra vizcaínos. Origen y expansión de una dinastía empresarial (1801-1890), Madrid, Fundación Empresa Pública, Documento de trabajo 9908.

DÍAZ MORLÁN, Pablo (2002): Los Ybarra. Una dinastía de empresarios, Madrid, Marcial Pons.

ESCUDERO, Antonio (1999): “Dos puntualizaciones sobre la historia de la siderurgia española entre 1880 y 1930", Revista de Historia Industrial, 15, pp. 191-200.

FERNÁNDEZ DE PINEDO, Emiliano (1983): “Nacimiento y consolidación de la moderna siderurgia vasca (1849-1913): el caso de Vizcaya", Información Comercial Española, 598, pp. 9-19.

-(1985): "Avances técnicos y consecuencias económicas en la siderurgia española del siglo XIX", en PESET, José Luis (ed.), La ciencia moderna y el nuevo mundo, Madrid, CSIC, pp. 39-53.

-(2001): “De la primera industrialización a la reconversión industrial: la economía vasca entre 1841 y 1990", en GERMÁN, Luis, LLOPIS, Enrique, MALUQUER DE MOTES, Jordi y ZAPATA, Santiago (eds.), Historia económica regional de Espana. Siglos XIX y XX, Barcelona, Crítica, pp. 95-124.

FRAILE, Pedro (1991): Industrialización y grupos de presión, Madrid, Alianza.

GIRONA, Manuel (1989): Minería y siderurgia en Sagunto, Valencia, Edicions Alfons el Magnànim.

GONZÁLEZ PORTILLA, Manuel (1985): La siderurgia vasca (1880-1901), Bilbao, Universidad del País Vasco.

JACQUEMIN, Alexis y SLADE, Margaret E. (1989): “Cartels, collusion and horizontal merger", en SCHMALENSEE, Richard y WILLIG, Robert D. (eds.), Handbook of Industrial Organization, Amsterdam, North-Holland, vol. 1, pp. 415-473.

MARTÍNEZ RUIZ, José Ignacio (1998): La Unión de Almacenistas de Hierros y la distribución de hierros comerciales en España, Madrid, Fundación Empresa Pública, Documento de trabajo 9806. 
NADAL, Jordi (1992): Moler, tejer y fundir, Barcelona, Ariel.

NADAL, Jordi y SUDRIÀ, Carles (1993): “La controversia en torno al atraso económico español en la segunda mitad del siglo XIX (1860-1913)", Revista de Historia Industrial, 3, pp. 199-228.

OJEDA, Germán (1985): Asturias en la industrialización española, 1833-1907, Madrid, Siglo XXI.

-(2000): Duro Felguera. Historia de una gran empresa industrial, Oviedo, Grupo Duro Felguera.

SÁEZ GARCÍA, Miguel Ángel (1997): “Los primeros carteles siderúrgicos (18711879)", VI Congreso de la Asociación de Historia Económica, actas de la $3^{a}$ sesión, pp. 211-225.

-(1999a): Álava en la siderurgia moderna española. San Pedro de Araya (1847-1935), Vitoria, Diputación Foral de Álava.

—(1999b): "El mercado español de hierros comerciales. El caso de San Pedro de Araya, 1867-1925", Revista de Historia Industrial, 15, pp. 11-40.

SEGURA, Julio (1993): Teoría de la economía industrial, Madrid, Civitas.

STIGLER, George J. (1964): "A theory of oligopoly", Journal of Political Economy, LXXII (1), pp. 44-61.

TORTELLA, Gabriel (1994): El desarrollo de la España contemporánea: historia económica de los siglos XIX y XX, Madrid, Alianza.

VALDALISO, Jesús M ${ }^{a}$ (1988): “Grupos empresariales e inversión de capital en Vizcaya, 1886-1913", Revista de Historia Económica, Año VI, 1, pp. 11-40.

-(1999): "Orígenes y desarrollo de la historia empresarial en España", Príncipe de Viana. Suplemento de Ciencias Sociales, 17, pp. 91-117. 


\begin{tabular}{|c|c|c|c|c|c|}
\hline \multirow{6}{*}{ 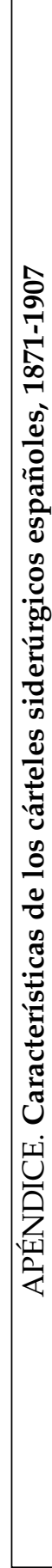 } & 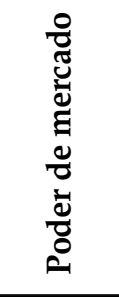 & 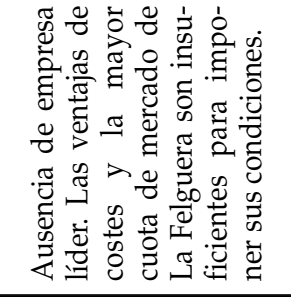 & 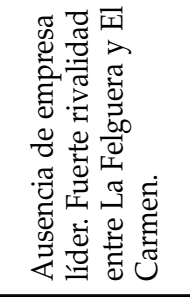 & 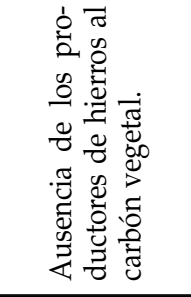 & 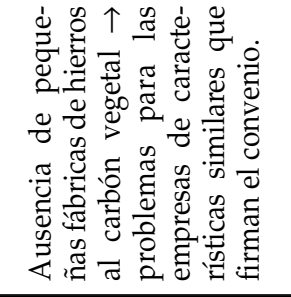 \\
\hline & 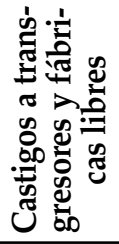 & 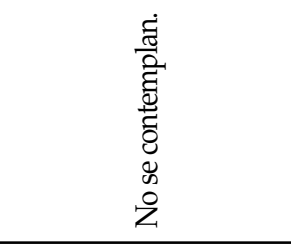 & 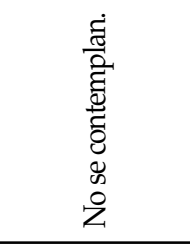 & 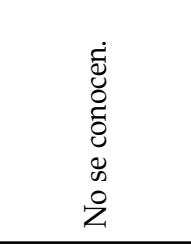 & 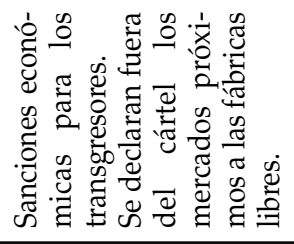 \\
\hline & 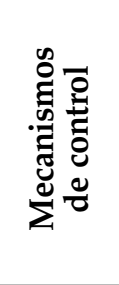 & 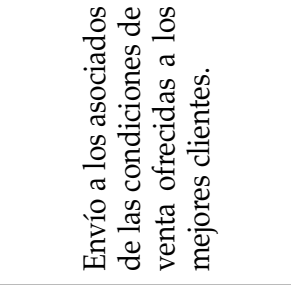 & 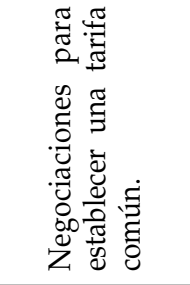 & 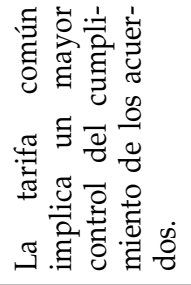 & 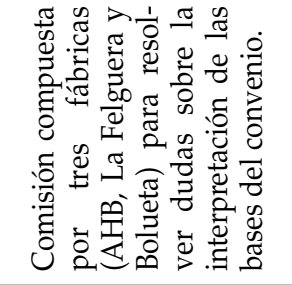 \\
\hline & 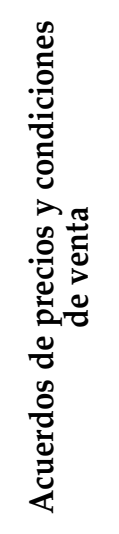 & 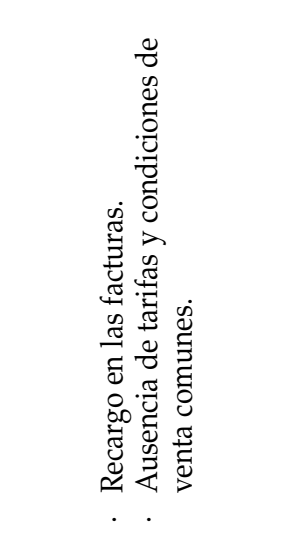 & 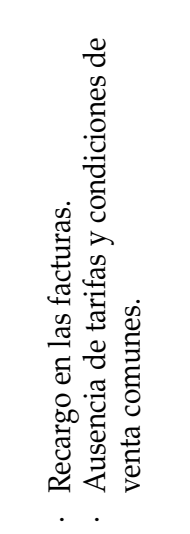 & 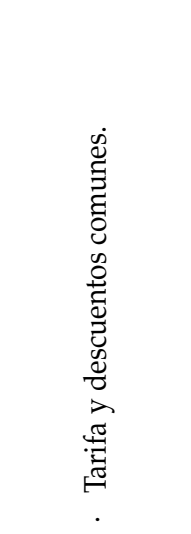 & 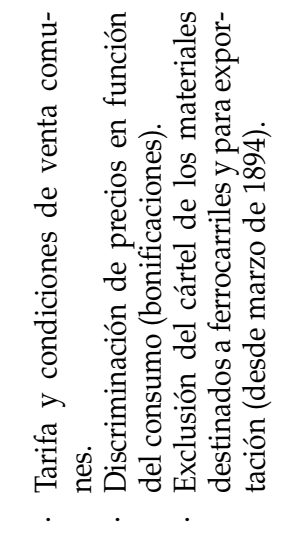 \\
\hline & 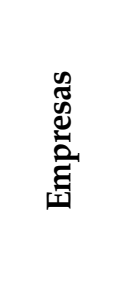 & 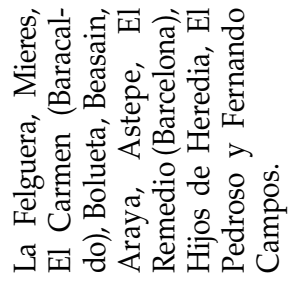 & 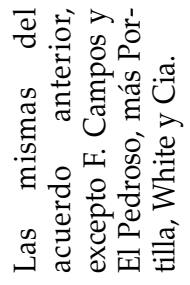 & 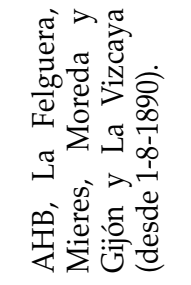 & 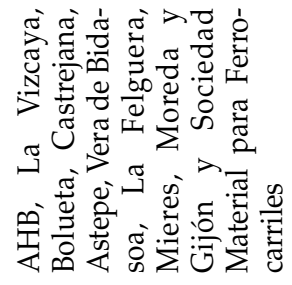 \\
\hline & 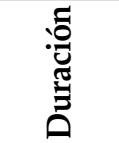 & 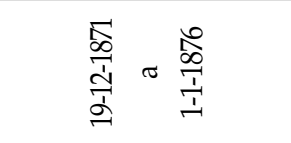 & 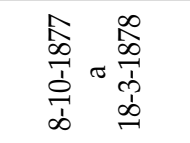 & 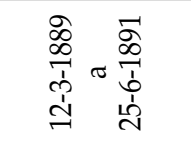 & 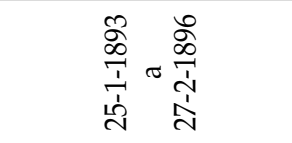 \\
\hline
\end{tabular}




\begin{tabular}{|c|c|c|c|}
\hline 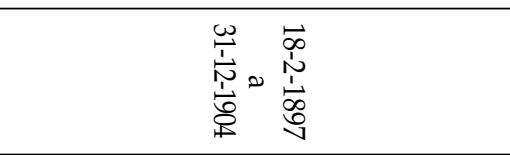 & 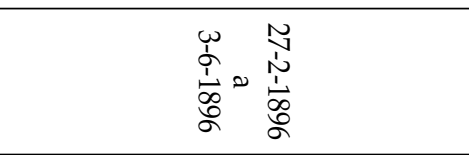 & 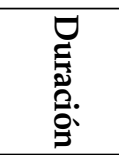 & \\
\hline 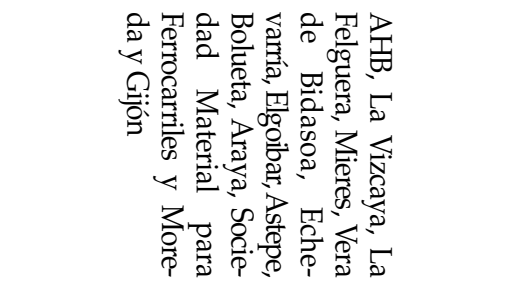 & 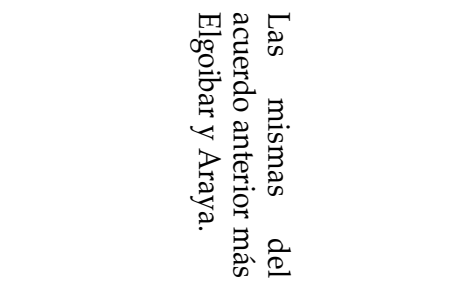 & 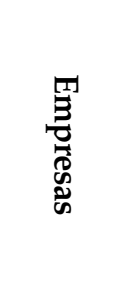 & 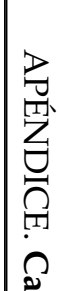 \\
\hline 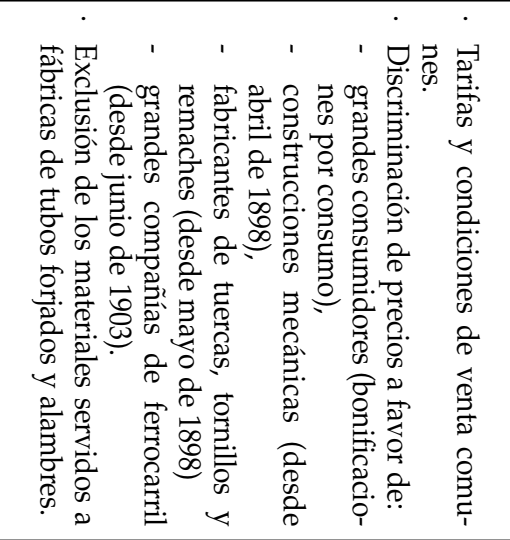 & 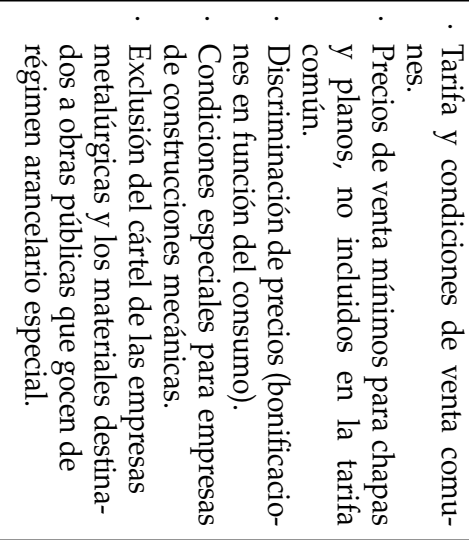 & 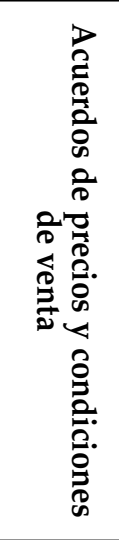 & 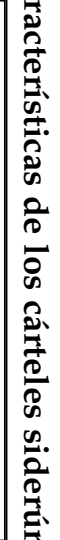 \\
\hline 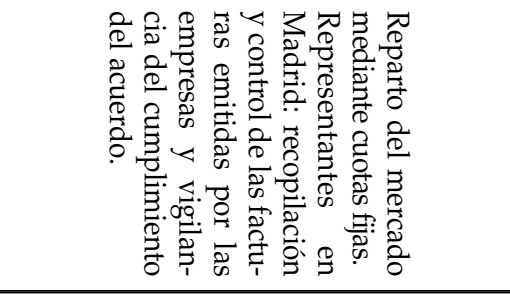 & 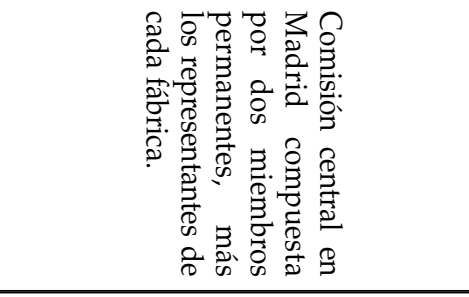 & 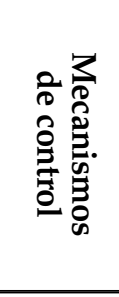 & 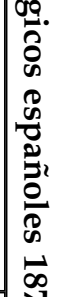 \\
\hline 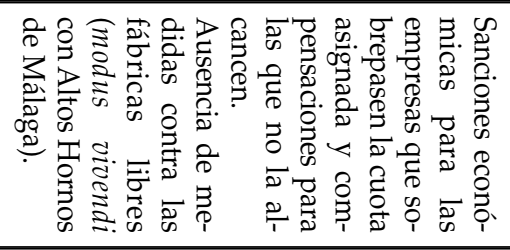 & 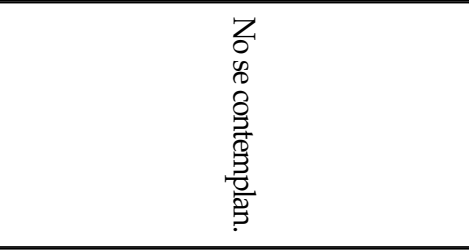 & 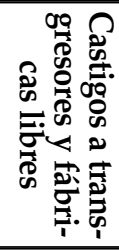 & 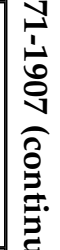 \\
\hline 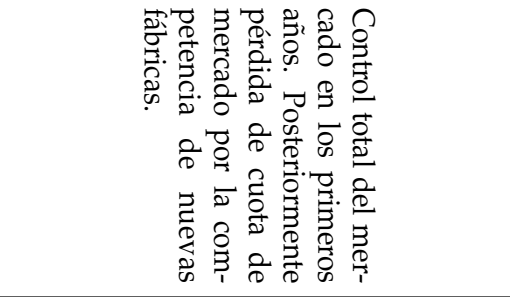 & 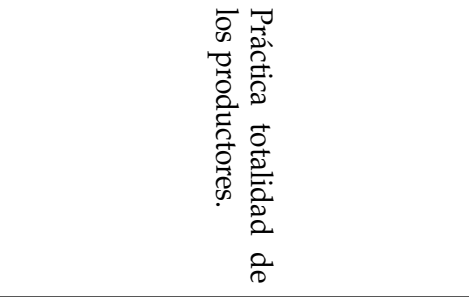 & $\begin{array}{l}\text { T} \\
0 \\
0 \\
0 \\
0 \\
0 \\
3 \\
0 \\
0 \\
03 \\
0 \\
0\end{array}$ & : \\
\hline
\end{tabular}




\begin{tabular}{|c|c|c|c|}
\hline \multirow{6}{*}{ 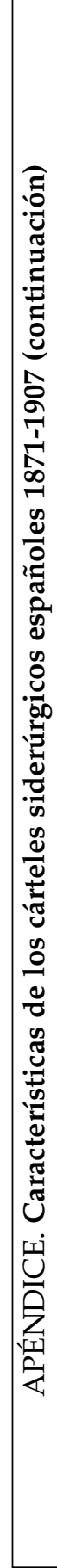 } & 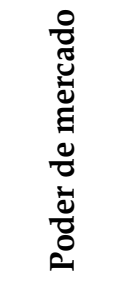 & 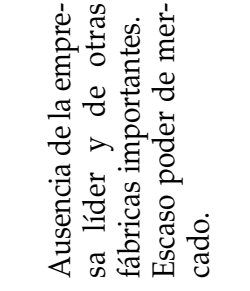 & 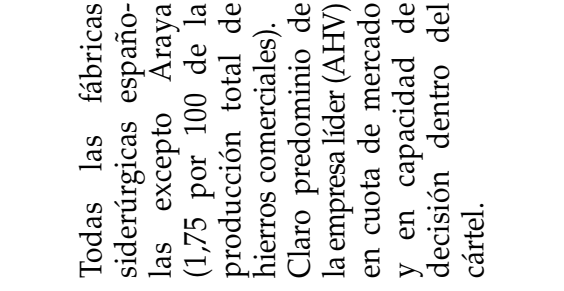 \\
\hline & 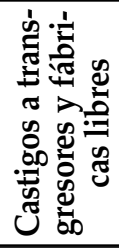 & 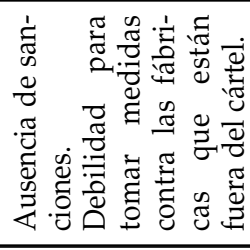 & 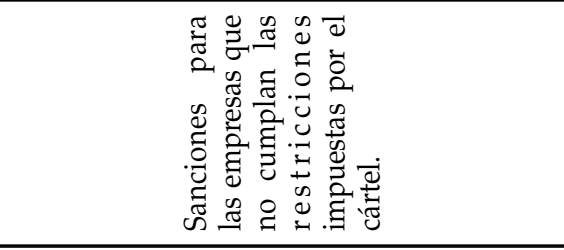 \\
\hline & 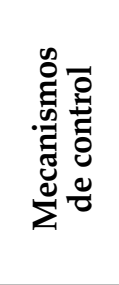 & 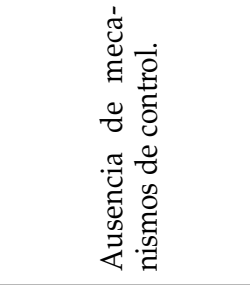 & 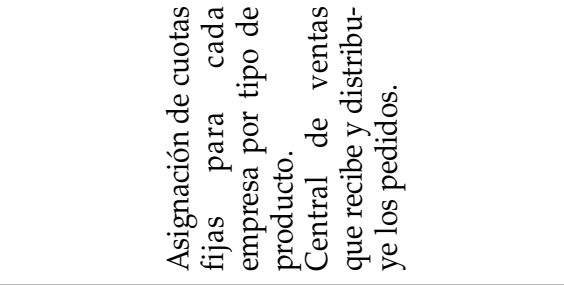 \\
\hline & 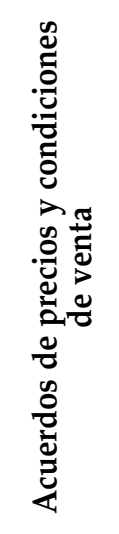 & 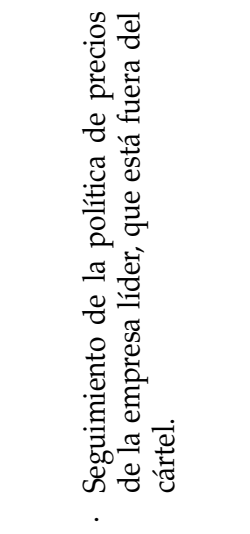 & 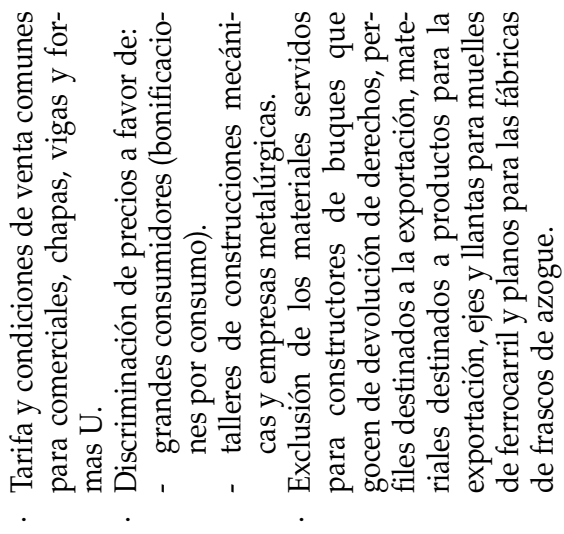 \\
\hline & 总 & 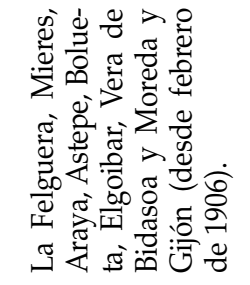 & 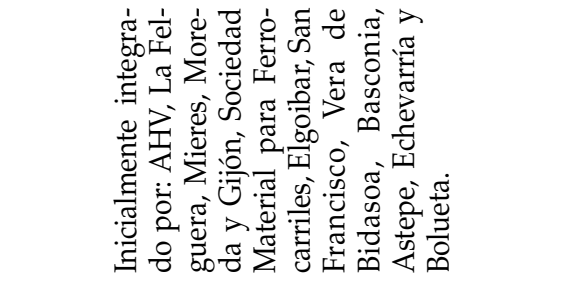 \\
\hline & 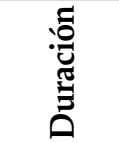 & 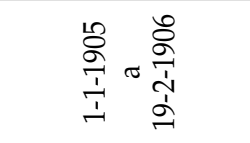 & 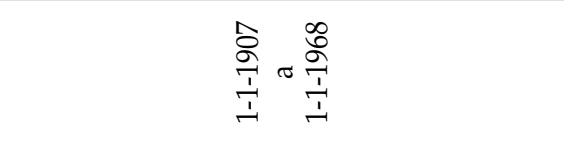 \\
\hline
\end{tabular}

